\title{
Produções Textuais em Espaços Digitais
}

Ana Teresinha Elicker

Universidade Feevale

anaelicker@hotmail.com

ORCID: https://orcid.org/0000-0003-1432-6506

Viviane Cristina de Mattos- Battistello²

vivimattos@feevale.br

ORCID: https://orcid.org/0000-0002-0482-8927

Rosemari Lorenz-Martins ${ }^{3}$

Universidade Feevale

rosel@feevale.br

ORCID: http://orcid.org/0000-0003-0658-5508

Maria Rosangela Bez

Universidade Feevale

mariabez@feevale.br

ORCID: https://orcid.org/0000-0001-9323-0419

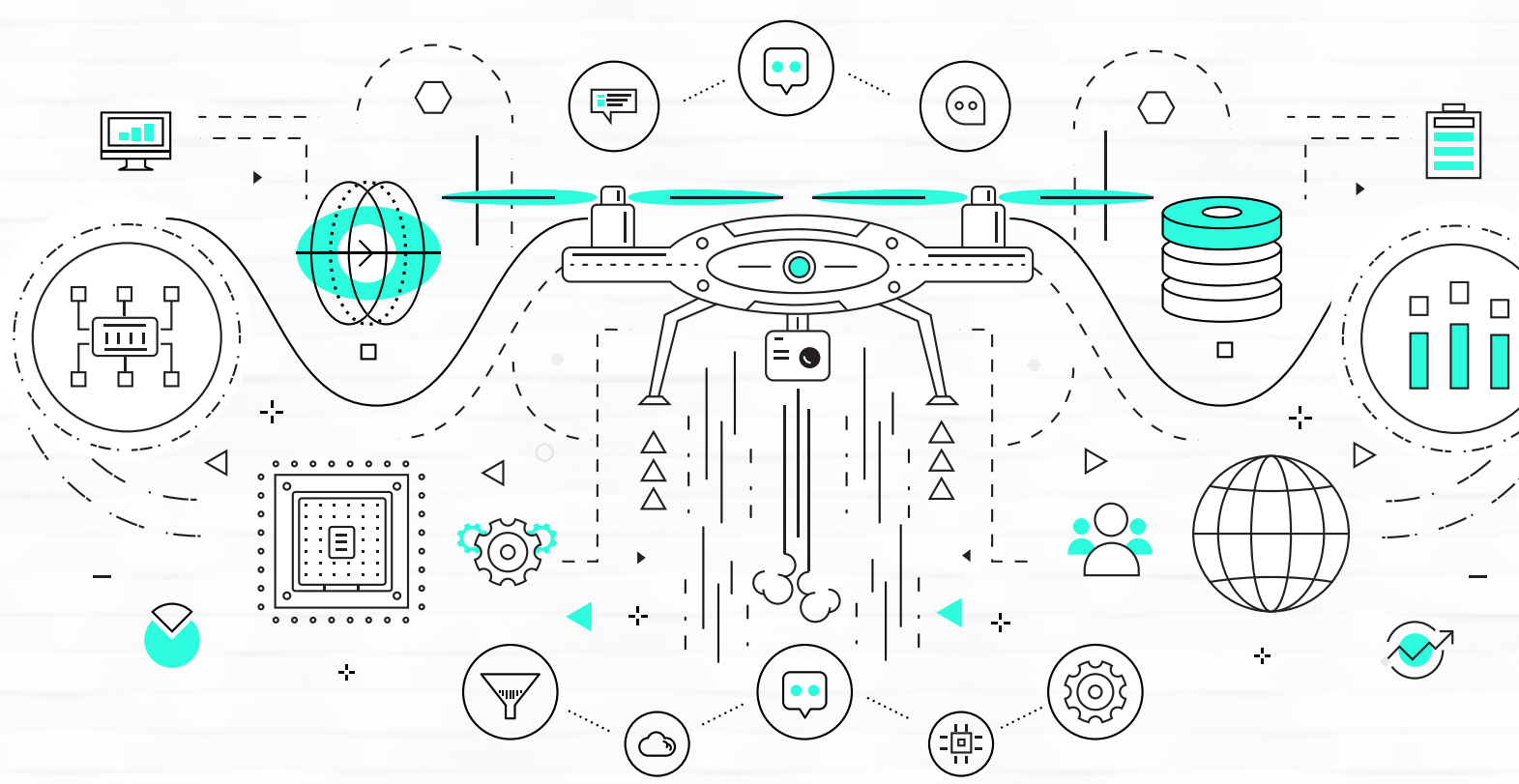

DOI: https://doi.org/10.21158/2357514x.v7.n1.2019.2321

Cómo citar este artículo: Elicker, A. T.; de Mattos- Battistello , V. C.; Lorenz-Martins, R.; Bez , M. R. (2019). Produções Textuais em Espaços Digitais. Revista Virtu@Imente, 7(1), 45-62. DOI: https://doi.org/10.21158/2357514x.v7.n1.2019.2321

Fecha de recepción: 21 de enero de 2019

Fecha de aprobación: 07 de marzo de 2019

${ }_{1}^{1}$ Doctoranda en Diversidade Cultural e Inclusão Social (Feevale). Magister en Letras (Feevale). Especialista en Gestão escolar (UFRGS). Especialista en EJA (PUC). Graduada en Letras (Feevale).

${ }^{2}$ Doctoranda en Diversidade Cultural e Inclusão Social (Feevale). Magister en Letras (Feevale). Graduada en Letras-Português/Inglês (Feevale) y graduada en Pedagogía (UNINTER). Especialista en Processo de Aquisição e Desenvolvimento da Linguagem (FEEVALE). Especialista en Psicopedagogía Clínica e Institucional (UNILASALLE). Especialista em Formação de Docentes e de Tutores (Orientadores acadêmicos) en EAD (UNINTER/2013). Especialista en Educação na Perspectiva do Ensino Estruturado para Autistas (INFOCO). Especialista en Educação Especial e Educação Inclusiva (UNINTER)

${ }^{3}$ Graduada en Letras- Português/Alemão. Especialista en Linguística do Texto y Magister en Ciências da Comunicação.(Universidade do Vale do Rio dos Sinos). Doctora en Letras por la Pontifícia Universidade Católica do Rio Grande do Sul.

${ }^{4}$ Graduada en Licenciatura em Computação pela Universidade Feevale (2007), Mestrado em Educação pelo Programa de Pós-graduação em educação da Universidade Federal do Rio Grande do Sul (2010). Doutora pelo Programa de Pós-graduação em Informática na Educação da UFRGS (2014). Pós-doutorado pelo Programa de Pós-Graduação em Diversidade Cultural e Inclusão Social, Feevale. 


\section{RESUMO}

O artigo tem como objetivo apresentar uma proposta pedagógica que envolva a produção de textos digitais multimodais de forma colaborativa, a partir de uma prática positiva com os alunos das séries finais do ensino fundamental de uma escola pública do Brasil.

A metodologia de pesquisa-ação do projeto partiu de uma conversa com os alunos, na qual se percebeu o interesse em escrever pelas redes sociais. Em seguida, o professor propôs as ferramentas de discussão e os textos digitais, utilizando tópicos fora do alcance de muitos alunos. Dessa forma, o grupo passou a utilizar as ferramentas dos documentos do Google, criando textos colaborativos, sendo coautores do projeto e redatores de seu próprio processo de ensino-aprendizagem, que se torna um auto discurso do grupo de alunos, o que é considerado uma prática que transcende a proposta escolar tradicional.

A leitura e a escrita de textos multimodais favorecem a multiliteração, expandindo a competência acadêmica e discursiva dos alunos, tão necessária para o desenvolvimento de habilidades individuais. A abordagem através de um objeto de amplo domínio por parte dos alunos os capacita e os incentiva a participar ativamente das aulas, compromete-os com seu processo de aprendizagem e fortalece os laços com os professores, ampliando a autonomia em suas competências de pesquisa.

Palabras clave: produção textual; processo ensino-aprendizagem; textos colaborativos; textos digitais; textos multimodais; multiliteração; ferramentas de discussão; competência discursiva. 


\section{Producciones textuales en espacios digitales}

\section{RESUMEN}

El artículo tiene como objetivo presentar una propuesta pedagógica que implique la producción de textos digitales multimodales de forma colaborativa, desde una práctica positiva con los estudiantes de la serie final de educación elemental de una escuela pública en Brasil.

La metodología de investigación-acción del proyecto comenzó a partir de una conversación con los alumnos, en la que se percibió el interés por escribir a través de las redes sociales. A continuación, el profesor propuso las herramientas de discusión y textos digitales, utilizando temas más allá del alcance de muchos estudiantes. De esta manera, el grupo comenzó a utilizar las herramientas de los documentos de Google, creando textos colaborativos, siendo coautores del proyecto y escritores de su propio proceso de enseñanza-aprendizaje, que se convierte en un auto-discurso del grupo estudiantil, lo que se considera como una práctica que trasciende una propuesta de escuela tradicional.

La lectura y escritura de textos multimodales favorece la multiliteración al expandir la competencia académica y discursiva de los estudiantes, tan necesaria para el desarrollo de habilidades individuales. El enfoque a través de un objeto de amplio dominio por parte de los estudiantes los empodera y los alienta a participar activamente en las clases, los compromete con su proceso de aprendizaje y fortalece los lazos con los profesores, ampliando la autonomía en su competencia investigativa.

Palabras clave: producción textual; proceso de enseñanza-aprendizaje; textos colaborativos; textos digitales; textos multimodales; multiliteración; herramientas de discusión; competencia discursiva. 


\section{Textual productions in digital spaces}

\section{ABSTRACT}

This article aims at presenting a pedagogical proposal that involves the production of multimodal digital texts in a collaborative way, from a positive practice with the students in the final series of elementary education of a public school in Brazil.

The research-action methodology of the project emanates from a conversation with the students, in which the interest in writing through social networks was perceived. After that, the professor proposed the discussion tools and digital texts, using topics beyond the reach of many students. In this way, the group began to use Google tools for documents, creating collaborative texts, and being co-authors of the project and writers of their own teaching-learning process, which becomes a self-speech of the student group, what is considered as a practice that transcends a traditional school proposal.

The reading and writing of multimodal texts favors multiliteration by expanding the academic and discursive competence of students, so necessary for the development of individual skills. The approach by means of an object of broad mastery on the part of the students empowers them and encourages them to actively participate in the classes, compromises them with their learning process, and strengthens the ties with the professors, extending the autonomy in their research competence.

Keywords: textual production; teaching-learning process; collaborative texts; digital texts; multimodal texts; multiliteration; discussion tools; discursive competition. 


\section{Productions textuelles en espaces numériques}

\section{RÉSUMÉ}

Cet article présente une proposition pédagogique impliquant la production collaborative de textes numériques multimodaux à partir d'une pratique d'élèves de dernière année de l'enseignement public brésilien.

La méthodologie du projet a commencé à partir d'une conversation avec des étudiants lors de laquelle est ressortie leur intérêt pour l'écriture au travers des réseaux sociaux. L'enseignant a alors proposé des outils de discussion et des textes numériques dont les thèmes dépassaient les connaissances de nombreux étudiants. Le groupe a dû commencer à utiliser les outils de Google Documents et à créer des textes collaboratifs en tant que co-auteurs du projet et auteurs de leur propre processus d'enseignement-apprentissage. Cette pratique alternative transcende la proposition scolaire traditionnelle dans la mesure où la lecture et l'écriture de textes multimodaux favorisent la multi-alphabétisation en élargissant les compétences académiques et discursives des étudiants, indispensables au développement des compétences individuelles. Une approche pédagogique via un objet largement maitrisé par les apprenants les habilite et les encourage à participer activement aux cours, les engage dans leur processus d'apprentissage et renforce les liens avec les professeurs, élargissant l'autonomie de leurs compétences investigatives.

Mots-clés: production textuelle; processus d'enseignement-apprentissage; textes collaboratifs; textes numériques; textes multimodaux; multilitération; outils de discussion; concurrence discursive. 


\section{Introducción}

Os recursos de tecnologia móvel têm seu uso ampliado entre os jovens de nossa sociedade. Vistos como ferramentas de construção efetiva e significativa do conhecimento, podem potencializar o ensino e a aprendizagem. Esses recursos são uma das formas de adquirir conhecimento e habilidades a partir de práticas pedagógicas e de mobilidade (Saccol, Schlemmer y Barbosa, 2010). Dessa forma, abre-se a possibilidade da interação e da colaboração, de modo que o aluno se torne um elemento ativo de sua aprendizagem.

Nesse contexto, insere-se o resultado de uma prática pedagógica de leitura e de produção de textos digitais multimodais de forma colaborativa com a utilização de celular, em um projeto de pesquisa-ação que durou um semestre letivo em uma turma de nono ano do Ensino Fundamental, de uma escola da rede municipal de uma cidade do interior do Rio Grande do Sul, no Brasil.

A cidade é pequena, tem vinte e um mil habitantes. A escola onde foi realizada a prática pedagógica, no bairro da pequena comunidade, fica próximo ao bairro central. A escola tem pouco mais de 200 alunos e poucos recursos didáticopedagógicos e de pesquisa para oferecer. A turma 191, na qual foi desenvolvido o projeto, possui 27 alunos, com idades entre 14 e 16 anos, os quais são amáveis e muito ativos, como a maioria dos adolescente. Grande parte dos alunos reside no bairro em que fica localizada a escola, apenas 2 alunos moram em uma localidade agrícola, distante $17 \mathrm{~km}$ da escola.

O projeto surgiu após a primeira conversa com os alunos, no início do ano letivo, em que ficou evidente, por meio da fala de um aluno «Oh! Eu não gosto, eu não sei escrever» que eles não gostavam de escrever na aula de Língua Portuguesa e que preferiam escrever no celular, conversar por meio de aplicativos como Whatsapp e Facebook e, além disso, faltavam-lhes ideias para pôr no papel.

Detectado o interesse dos alunos pela escrita em redes sociais, a professora os convidou para escolherem o assunto a ser estudado e as ferramentas tecnológicas a serem utilizadas, temas fora do alcance de muitos deles, porque a maioria só tem celular, não tem notebooks ou desktops em casa.

Dessa forma, o grupo chegou ao texto no Google Docs ${ }^{5}$ Utilizando essa ferramenta, os alunos poderiam ser coautores do projeto da professora e autores de seu próprio processo de aprendizagem.

\footnotetext{
5 "O Google Docs, é um pacote de aplicativos do Google baseado em AJAX. As ferramentas do Google Docs funcionam de forma síncrona e assíncrona, portanto, on-line para acessar dados em nuvens e off-line através de aplicativos de extensão instaladas diretamente do google, onde há bancos de dados criados por essa extensão para posterior sincronização através de upload instantâneo ao acessá-los online, diretamente no browser de desktops ou aplicativos de dispositivos móveis do Android e Mac. Os aplicativos são compatíveis com o OpenOffice.org/BrOffice.org, KOffice e Microsoft Office, e atualmente compõem-se de um processador de texto, um editor de apresentações, um editor de planilhas e um editor de formulários". Site oficial, 2019.
} 


\section{Metodologia}

A fim de buscar motivação para a produção de textos nas aulas de Língua Portuguesa, optou-se por escrever em espaço digital, após observação da enorme habilidade com que os alunos manuseavam seus celulares. Isso ocorre, possivelmente, porque «algo absolutamente novo está acontecendo: o uso das novas tecnologias pelos nativos digitais [...] está provocando mudanças no nosso entendimento de identidade» (Palfrey y Gasser, 2011). Essa mudança passa da identidade pessoal e afeta a identidade social, uma vez que a multiplicidade de identidade online ou off-line dos adolescentes é comum aos nativos digitais (Palfrey y Gasser, 2011).

Buscando aproximar a escola a esse novo contexto, optou-se por desenvolver com os alunos uma pesquisa-ação, que consistiu num trabalho colaborativo com os participantes através da constante revisão dos processos de ensino-aprendizagem por meio de uma relação dialógica, envolvendo a díade professor-aluno. Esse é um processo importante, uma vez que pressupõe passos a serem dados juntos, em que a continuidade se sobrepõe à previsibilidade, pois «a pesquisa-ação educacional é principalmente uma estratégia para o desenvolvimento de professores e pesquisadores de modo que eles possam utilizar suas pesquisas para aprimorar seu ensino e, em decorrência, o aprendizado de seus alunos» (Tripp, 2005). «Dessa forma, todos nós aprendemos com a experiência, mas podemos também registrar o que aprendemos a fim de esclarecê-lo, disseminá-lo entre os colegas e acrescentá-lo ao estoque de conhecimento profissional sobre a docência» (Tripp, 1996).
Assim, para a construção do projeto, foi proposta uma discussão em sala de aula orientada pela professora de português, momento em que o assunto foi discutido com o grupo de alunos, a fim de escolher a temática da pesquisa do projeto de produção de textos no ambiente digital. Cabe destacar que, embora o trabalho tenha sido desenvolvido na aula de Língua Portuguesa, os textos produzidos pelos alunos relacionaram-se com assuntos trabalhados em outras disciplinas, como Ciências e Ensino Religioso, por exemplo, tornando-os multidisciplinares. Além disso, procurou-se colocar em prática de forma efetiva o "processo de reflexão», para o que todo o grupo utilizou diversos instrumentos de registro, tais como notas de campo, fotografias, conversas estruturadas, questionários de avaliação, colagem descritiva, relatórios da professora-pesquisadora (Aragão, 2012). No que tange à pesquisa-ação, o projeto contemplou as quatro fases importantes: planejamento, ação, observação e reflexão, permanentemente articuladas, porque o processo é tão ou mais importante que o resultado final (Esteban, 2010).

Nessa perspectiva, a utilização da pesquisa-ação pode colaborar para uma prática docente mais responsiva às demandas da sociedade, trazendo consigo discussões sobre cidadania, questões de inclusão/exclusão, relações de poder e conhecimento, protagonismo dos estudantes, ética, diversidade cultural e globalização (Oliveira, 2012; Paiva, 2019). Ademais, o resultado de uma prática pedagógica por meio da 
produção de textos multimodais apresenta importante caráter processual e contínuo. Isso, todavia, implica uma atenção maior ao contexto no qual se almeja promover mudança.

\section{A produção de textos em espaços digitais}

A produção de textos multimodais pode ser vista como uma prática que transcende a proposta tradicional de ensino, como «novas formas de competências nestes tempos» (Rojo, 2013). Isso provoca uma ruptura do modelo clássico de ensino de língua e da gramática normativa, por meio do uso de um novo ambiente de aprendizagem, mais interativo e dinâmico, com novos textos multimodais, com novas mídias, ampliando a capacidade de produção de texto e de leitura crítica, considerando que letramento é sempre letramento em algum gênero.

Fato é que a leitura e a escrita e as práticas pedagógicas delas decorrentes precisam ser revisitadas, pois, para além da cultura do impresso - ou da palavra escrita-, que deve continuar tendo centralidade na educação escolar, é preciso considerar a cultura digital, os multiletramentos, os novos letramentos ${ }^{6}$ entre outras denominações que procuram designar novas práticas sociais e de linguagem (Brasil, 2018).
Com esse tipo de prática, utilizando ferramentas digitais, o aluno alfabetiza-se e torna-se letrado no mundo digital. Em função disso, ao construir o projeto, foi levado em conta o letramento e o conhecimento de mundo dos alunos, nativos digitais, respeitando suas ideias e acolhendo seus questionamentos, uma vez que «eles também desenvolvem a abordagem multidisciplinar, multimodal do significado, que é um dos principais interesses do Projeto de Multiletramentos» (Cope y Kalantziz, 2005).

Dessa forma, o projeto já está em consonância com os novos paradigmas postulados pela nova Base Nacional $\mathrm{Cu}-$ rricular Comum brasileira, aprovada em 2018, segundo a qual, considerando-se o campo das práticas investigativas, deve haver "uma ênfase nos gêneros didático-expositivos, impressos ou digitais, do $6^{\circ}$ ao $9^{\circ}$ ano, sendo a progressão dos conhecimentos marcada pela indicação do que se operacionaliza na leitura, escrita, oralidade» (Brasil, 2018).

Em uma proposta desse tipo, o texto deixa de ser um objeto apenas teórico, embora respeite a materialidade de sequências organizadas, com sinais convencionais, elementos linguísticos e estruturas sintáticas devidamente organizadas, produzindo sentido, em um todo coerente e coeso, e passa a ser um discurso autoral do grupo de alunos. Assim, chegou-se a um texto que pode ser definido, como «objeto da atividade autoral de mobilização e de recursos para a realização de um projeto enunciativo a partir da relação locutor-interlocutor» (Sobral, 2019). 
Nesse contexto, a construção do projeto com o grupo de alunos foi considerada uma aula de produção de texto que seguiu uma estrutura de projeto de pesquisa. Os alunos nunca tinham participado de uma proposta desse tipo. Ademais, por terem podido escolher o assunto da pesquisa, os alunos sentiram-se mais responsáveis, pois não foi uma tarefa imposta, mas uma escolha da maioria dos colegas. Isso os motivou a participar mais. O professor/coordenador e os demais professores, os das outras disciplinas, iam inserindo seus conteúdos no projeto na medida do possível.

Esse tipo de atividade, contudo, requer sujeitos com conhecimento do mundo digital, com noções básicas de uso de recursos tecnológicos. No caso deste estudo, os alunos, assim como grande parte dos adolescentes do mundo inteiro, já sabiam manusear diferentes tipos de ferramentas. Todavia, «há modos em que podemos interessar os nativos digitais e tirar vantagem da maneira particular pela qual eles aprendem. Vamos tirar proveito do fato de que eles têm computador diante deles e a habilidade para usá-lo» (Palfrey y Gasser, 2011). Os mesmos autores salientam, contudo, que «a tecnologia só deve ser aplicada em apoio à nossa pedagogia, não por si só» (Palfrey y Gasser, 2011), ou seja, deve-se aproveitá-la como ferramenta pedagógica e não como ponto central de uma aula. Desse modo, a tecnologia torna-se uma ferramenta que possibilita a prática efetiva e motivadora da criação de textos, oportunizando o uso do letramento em espaços digitais.

\section{O texto colaborativo e o letramento nos espaços digitais}

No universo singular de cada escola, encontram-se alunos nascidos na era digital que não tiveram acesso à internet, os que interagem apenas em redes gratuitas de acesso limitado e ainda os que têm acesso livre a ela e a usam com frequência. Para realizar um trabalho como o que está sendo apresentado, os alunos devem conhecer a ferramenta a ser utilizada e ter acesso a ela, de forma individual ou coletiva. Todavia, «os letramentos da era da informação não são apenas sobre fazer e usar a multimídia. Eles também incluem 'letramentos informáticos». Sendo assim, os alunos devem, segundo o mesmo autor, desenvolver «habilidades para categorizar e localizar informações e objetos e apresentações multimidiáticos» (Lemke, 2010). Isto é, os alunos não devem se sentir excluídos digitais, no sentido de não serem alfabetizados digitais.

Cabe destacar que há uma diferença entre o analfabeto digital, aquele que não sabe utilizar os recursos, mesmo tendo acesso a eles, e o excluído digital, que é aquele que não tem acesso às ferramentas por questões sociais ou pessoais. Incluir, ou seja, proporcionar o acesso às variadas formas de tecnologias e auxiliar para o desenvolvimento do domínio das ferramentas do mundo digital é de significativa relevância para o processo de aprendizagem e de letramento 
digital. A integração do aluno com a tecnologia é essencial para oportunizar o conhecimento de novas formas de leitura e para ampliá-las em um processo de ensino e aprendizagem em que a interação entre os alunos e o professor ofereça novos conhecimentos.

De acordo com a BNCC, é necessário que o aluno tenha acesso a «softwares de edição de textos, fotos, vídeos e áudio, além de ferramentas e ambientes colaborativos para criar textos e produções multissemióticas com finalidades diversas, explorando os recursos e efeitos disponíveis e apropriandose de práticas colaborativas de escrita, de construção coletiva do conhecimento e de desenvolvimento de projetos» (Brasil, 2018).

Nessa perspectiva, é importante favorecer a produção de textos colaborativos no cotidiano escolar, embora os processos de aprendizagem sejam individuais, pois, apesar de cada um ter um tempo de aprendizagem diferente e de ter capacidades diferentes, o trabalho colaborativo, na maior parte das vezes, é mais prazeroso do que o individual, especialmente em função do compartilhamento de ideias, que agrega maior informação e possibilita mais situações de aprendizagem.

Além disso, esses pressupostos estão alinhados à BNCC, cujo propósito é «possibilitar que vivenciem processos colaborativos de apuração de fatos tidos como de relevância social, por meio de coberturas diretas, entrevistas, levantamentos de dados e afins e tratamento e divulgação de informações sobre esses fatos, utilizando ferramentas de escrita colaborativa e de curadoria e agregadores de conteúdos, pois a linguagem utilizada pelo grupo acaba favorecendo os alunos que têm mais dificuldades, os quais acabam atingindo um desempenho melhor nesse tipo de atividades» (Brasil, 2018).

Cabe destacar que todo letramento é multimidiático porque os textos são, em sua grande maioria, multimidiáticos. Sendo assim, não é possível construir significados linguísticos a partir de palavras isoladas. É preciso levar em conta as realizações visuais ou vocais de signos linguísticos que também carregam significados não linguísticos — por ex.: tom da voz ou estilo da ortografia-. Para funcionarem como signos, essas realizações devem ter alguma realidade material, mas toda forma material carrega, potencialmente, significados definidos por mais de um código. Toda semiótica é semiótica multimídia e todo letramento é letramento multimidiático [8].

Todos os textos são multimodais. Isso porque «a língua sempre tem de ser realizada por meio de, e vem acompanhada de, outros modos semióticos» (Kress y Van Leeuwen, 1998). Afirmar isso significa admitir uma abordagem do texto em camadas, isto é, significa admitir que existe uma «ligação inextricável entre o texto e sua materialidade, que precisa ser considerada» (Riberiro, 2013). Sendo assim, «é fundamental lembrar que nenhum texto existe fora do suporte que the confere legibilidade; qualquer compreensão de um texto, não importa de que tipo, depende das formas com as quais ele chega até seu leitor» (Rojo, 2018).

A multimodalidade não se deve, contudo, somente ao desenvolvimento das TICs, mas também à grande variedade de culturas em que estamos inseridos. Desse modo, para 
compreender os textos multimodais e para se comunicar nesse contexto, são necessários novos letramentos ou multiletramentos.

O conceito de multiletramentos aponta para dois tipos específicos e importantes de multiplicidade: a multiplicidade cultural das populações e a multiplicidade semiótica de constituição dos textos por meio dos quais ela se informa e se comunica (Gomes, 2017).

Os textos digitais, conforme (Gomes, 2017), «são interativos; são colaborativos e eles são híbridos, fronteiriços, mestiços». Assim sendo, o melhor lugar para eles existirem é 'nas nuvens' ${ }^{\prime 7}$ e a melhor maneira de se apresentarem é na estrutura ou formato de redes - hipertextos, hipermídias-» (Rojo, 2018). A escola não pode ignorar tudo isso. Ela precisa reconfigurar seus processos de ensino-aprendizagem «às novas configurações que se apresentam no mundo contemporâneo e globalizado e [...] tomar para si a tarefa de trabalhar com esses novos modos de ver/sentir/agir e de significar o mundo e a realidade social» (Gomes, 2017). Foi considerando-se tudo isso que se desenvolveu a prática pedagógica de escrita de textos colaborativos e de letramento no espaço digital, apresentada neste artigo.

\section{A construção do texto —análise-}

Para desenvolver o trabalho aqui apresentado, num primeiro momento, antes mesmo de colocar em prática o projeto, debateu-se, com os alunos, sobre a linguagem utilizada nas redes sociais e sobre a norma padrão da língua portuguesa. Na forma coloquial —usada nas redes sociais_, por exemplo, nem sempre é usada letra maiúscula no início da frase, também não há preocupação com os sinais de pontuação, que não são usados de acordo com o padrão da língua, conforme pode ser visualizado no Quadro 1.

Quadro 1. Comparativo da Norma Coloquial e Norma Padrão

\begin{tabular}{|c|c|}
\hline Norma coloquial & Norma padrão \\
\hline oi td bem & Oi, tudo bem? \\
\hline vamo no centro hj & Vamos ao centro hoje? \\
\hline ta fzd oq? & O que você está fazendo? \\
\hline bjs & Beijos \\
\hline
\end{tabular}

Fonte. Autoria dos alunos

Em decorrência dessa discussão, à medida que novos textos iam sendo apresentados aos alunos, a professora notou que as palavras abreviadas usadas nas redes sociais já não apareciam com tanta frequência nos textos produzidos em 
aula. Uma das cobranças nas produções de texto era o cuidado com a língua padrão. A professora solicitou aos alunos que tentassem utilizar em seus textos a linguagem padrão e que buscassem redigir textos coesos e coerentes, diferentemente dos textos produzidos em chats e em redes sociais. Pediu a eles também que evitassem o uso de palavras abreviadas e/ou reduzidas, que são aceitas em textos redigidos rapidamente em redes sociais, como, por exemplo, as palavras vc - você; tbm - também, tvz - talvez e outras tantas utilizadas para agilizar o fluxo comunicativo. Em função do pedido da professora, observou-se um cuidado maior nas reescritas dos textos expostos na páginas do documento da turma, dentro do Google Docs.

Desse modo, o texto produzido de forma colaborativa foi sendo tecido seguindo as normas da língua padrão.

Após a conclusão dos textos, os alunos foram convidados a relerem o que tinham escrito. Nesse momento, a professora solicitou que prestassem atenção na grafia correta das palavras, na coesão e na coerência do texto. Pediu também que buscassem o sentido dos textos produzidos e que os comparassem com os textos lidos ao longo do projeto, de outros autores.

A aproximação dos textos dos alunos com outros textos torna as produções textuais dos discentes um pouco melhores a cada nova leitura. Por isso, quanto mais contato com novos e diferentes textos eles puderem ter, melhor e maior será seu aprendizado, pois aprendemos a ler bem treinando leitura e a escrever bem escrevendo e reescrevendo. Conforme a BNCC: nesse processo, procedimentos e gêneros de apoio à compreensão são propostos em todos os anos. Esses textos servirão de base para a reelaboração de conhecimentos, a partir da elaboração de textos-síntese, como quadrosinópticos, esquemas, gráficos, infográficos, tabelas, resumos, entre outros, que permitem o processamento e a organização de conhecimentos em práticas de estudo e de dados levantados em diferentes fontes de pesquisa. Será dada ênfase especial a procedimentos de busca, tratamento e análise de dados e informações e a formas variadas de registro e socialização de estudos e pesquisas que envolvem não só os gêneros já consagrados, como apresentação oral e ensaio escolar, como também outros gêneros da cultura digital - relatos multimidiáticos, verbetes de enciclopédias colaborativas, vídeos-minuto etc. Trata-se de fomentar uma formação que possibilite o trato crítico e criterioso das informações e dados (Brasil, 2018).

No universo dos nascidos digitais, «há modos em que podemos interessar aos nativos digitais e tirar vantagem da maneira particular com que eles aprendem» (Brasil, 2018). Reconhecer e ter acesso às habilidades que eles têm e utilizar essas ferramentas para melhorar as competências comunicativas de leitura e escrita é função do professor.

\section{Resultados e discussão}

Para a produção de textos de forma colaborativa, utilizando o Documentos Google no Google Drive, nos celulares ou nos notebooks da escola, os alunos precisaram ter conhecimentos sobre gêneros textuais utilizados, precisaram saber qual a finalidade de cada um desses gêneros e como ele se 
caracterizam. Além de disso, precisaram ter conhecimento sobre o dispositivo que utilizaram para efetuar as tarefas. Clareadas essas questões, foram formados os grupos. Feito isso, identificou-se que a maioria dos alunos tinha apenas celular com acesso limitado à internet ou estavam sem acesso por falta de créditos assim, a internet da escola foi disponibilizada.

Os aparelhos celulares dos alunos eram de boa qualidade, assim todos os grupos tinham as ferramentas necessárias e o acesso ao Documentos Google. O que chamou a atenção da professora foi o fato de os alunos não conhecerem as funções e as opções de seus dispositivos móveis, pois se limitavam a usar os aparelhos para bate-papo em redes sociais. Todavia, eram bastante ágeis para usar os aplicativos, assim, familiarizaram-se rapidamente com o processador de texto e logo já digitaram textos nas pequenas máquinas. Todo o processo foi simultaneamente acompanhado pela professora.

Dessa forma, os alunos puderam elaborar entrevistas, relatórios e textos explicativos a partir das pesquisas que realizaram sobre alimentos, assunto que o grupo escolheu para investigar. Os conteúdos gramaticais específicos previstos para o ano, tais como: orações -e suas formas-, pronomes, verbos, formação e estrutura das palavras, concordância, semântica e sintaxe, foram abordados pela docente a partir dos textos produzidos pelos alunos, considerando suas dificuldades, por meio de atividades constantes de escrita, de leitura, de revisão dos textos e de reescrita. Assim, promoveuse o desenvolvimento da competência discursiva e uma maior autonomia em relação ao uso do idioma materno.
Abaixo, como exemplo, apresenta-se um texto (relatório de visita) no qual foram inseridas fotografias para ilustrar o texto (Figura 1), produzido por um dos grupos após uma saída de campo realizada durante o desenvolvimento do projeto, atividade que contou com o apoio das disciplinas de Ciências e de Ensino Religioso.

Figura 1. Texto exemplo

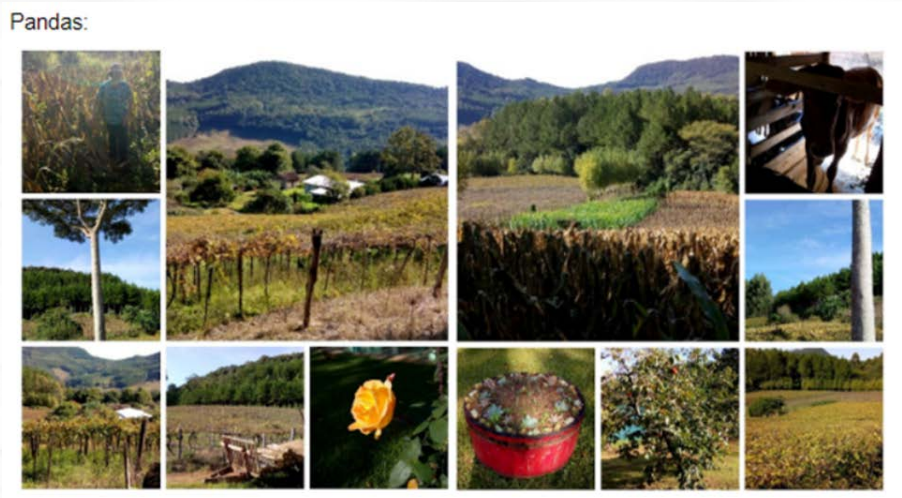

Fomos até a casa de dona Vitória, na Boa Esperança, Rolante/RS. Onde ela nos contou de suas técnicas agricolas (o que planta, o que coloca em suas plantas como defensivos agricolas, o tempo certo de plantio, o que produz, suas criaçőes, etc)

Algumas de suas plantações é o milho (depois de passar pelo secador é feito a quirera e dado aos porcos), parreirais de uva, caqui, feijão, laranja, verduras, lima, batata doce, mandioca, pinhão, banana, amendoim, pipoca, cana de açúcar, limão siciliano, butiá, figo, bergamota, goiaba, plantas medicinais... Ela produz, queijo, vinho (com uva bordô, champanhe, branca, pinot e rosé), linguiça, mel, leite. Tem criações de porcos, gado, galinha, abelha, gato, cachorro, gatos, peixes

Ela foi nossa guia, e nos mostrou cada canto, cada coisa, no final, paramos para conversar e comer um lanche, deu alguns de seus sucos e bolacha de melado, para experimentarmos. Aprendemos muito, foi uma expedição 10/10.

Fonte. Autoria própria

Para avaliar o progresso dos alunos neste projeto, optou-se pelo uso de um diário das atividades. Esse é um instrumento adequado para tal, na medida em que se tratou de uma pesquisa-ação, na qual todos os sujeitos devem 
estar envolvidos para que o projeto se desenvolva e traga resultados positivos. Embora o foco do projeto fosse a produção textual com autonomia, nas aulas de português, foi dispensado tempo também para a leitura e interpretação textos. O livro didático não foi totalmente abandonado, ele continuou sendo usado para a realização de atividades e para revisar alguns conteúdos específicos.

Para dar início ao projeto, os alunos criaram grupos - por afinidade- e os nomearam —todos optaram por usar nomes de animais- Depois disso, organizou-se uma pasta no drive e criaram-se documentos com o nome dos alunos. Cada grupo criou também um e-mail e uma senha para acessar o ambiente e construir sua página. Os textos e as informações postados nessas páginas ficaram abertos aos componentes do grupo, de modo que qualquer integrante pudesse interferir no texto do colega e auxiliá-lo em sua produção escrita, tornando os textos colaborativos. Concluídas as etapas de organização, passou-se às produções, divididas em tarefas e cada tarefa envolvia um texto, dentre os gêneros estudados na série, segundo o plano de conteúdos escolar.

Para avaliar os alunos, tomaram-se como critérios a autonomia e o comprometimento. Segundo um dos grupos, ao registrar a avaliação final, «com esse projeto, tivemos a oportunidade de melhor trabalhar em grupo e ter em uma única tarefa opiniões diferentes dadas pelos componentes». Verifica-se, assim, que o objetivo foi alcançado. Ainda no mesmo texto, os alunos escreveram que, «apesar de uma [aluna] não participar das tarefas, com o restante do grupo ajudando, aprendemos coisas como variedades linguísticas de textos - biografia, entrevista, comentários entre outros-».
Esse relato aponta a não participação efetiva de um dos componentes de um grupo de seis alunos, o que mostra o quanto são coerentes e responsáveis, pois todos assinaram a avaliação, inclusive a aluna que ficou com nota menor.

Concluídas as etapas de organização, passou-se para as produções, divididas em tarefas: Tarefa 1. Depois de criar o grupo e de nomeá-lo relatar os critérios de escolha dos participantes e do nome do grupo e colocar uma foto. Tarefa 2. Escrever sobre a escola e colocar uma foto da escola. Tarefa 3. Escrever um texto informativo sobre o município de Rolante com, no mínimo, 2 fotos (1 atual e 1 antiga). Tarefa 4. Incluir uma foto individual com a camisa da escola, escrever um texto biográfico. Conversar com alunos a respeito da metodologia de projeto. Levantar questões e temas - após conversas individuais e em grupos, os alunos apontam assuntos que gostariam que fossem estudados por eles. Entre os temas: como viver da roça; como são os produtos orgânicos; quem são e como vivem os colonos; a horta como segundo turno de trabalho; o que é agricultura familiar; o que a cidade de Rolante produz(...). Selecionar o tema através de votação, escolheu-se o tema agricultura familiar e produtos orgânicos. Delimitar o tema: pensou-se em fazer duas saídas de campo, uma na localidade da Boa Esperança e outra em um bairro próximo à escola, locais onde a maioria dos alunos vive. Diagnóstico do projeto - este levantamento foi feito oralmente - o que se sabe sobre o assunto - $O$ que sabemos e o que queremos saber? Onde pesquisar? Tarefa: Produzir relatório por etapas. Tarefa 5: Saída de campo para a localidade da areia —escolha dos alunos- para visitar uma família e se inteirar da rotina familiar, para verificar como a família retira da terra seu sustento. Tarefa 6: Pesquisa - $O$ 
que podemos pesquisar? Cada grupo faz sua escolha. registrar e após apresentar a pesquisa à turma. Pesquisa 1. O piretro - plantio, colheita - e como é feito o boa noite (o grupo responsável deverá trazer uma muda da planta, para nosso cultivo); Grupo Pandas; Pesquisa 2. fumo - tabaco (o grupo responsável deverá trazer uma muda da planta, para nosso cultivo); Grupo Pantera negra; Pesquisa 3. Precisamos conhecer/saber - como se faz o «veneno» não químico (trazer amostras das plantas) - Grupo Guaxinin; Pesquisa 4. plantas comuns e outras exóticas (cultivo em hortas) Grupo Koalas; Pesquisa 5. plantas comuns e outras exóticas (cultivo em roça) - Grupo Corujas.

Para avaliar o trabalho realizado pelo grupo, usaram-se as planilhas que seguem:

Quadro 2. Planilhas para avaliar o trabalho realizado

\section{Avaliação final - Panda}

\begin{tabular}{|c|c|c|c|c|c|}
\hline & Pandas & Guaxinin & Pantera & Corujas & Koalas \\
\hline Criatividade & 7,5 & 7,5 & 7 & 7,5 & 9 \\
\hline conteúdo & 9,5 & 7 & 7 & 7,5 & 9,5 \\
\hline contribuição & 8,5 & 7,5 & 7 & 8 & 9 \\
\hline
\end{tabular}

\section{Avaliação final - Guaxinin}

\begin{tabular}{|c|c|c|c|c|c|}
\hline & Pandas & Guaxinin & Pantera & Corujas & Koalas \\
\hline Criatividade & 70 & 90 & 70 & 95 & 95 \\
\hline conteúdo & 95 & 95 & 90 & 95 & 90 \\
\hline contribuição & 70 & 100 & 95 & 100 & 100 \\
\hline
\end{tabular}

\section{Avaliação final - Pantera}

\begin{tabular}{|c|c|c|c|c|c|}
\hline & Pandas & Guaxinin & Pantera & Corujas & Koalas \\
\hline Criatividade & 75 & 80 & 80 & 90 & 80 \\
\hline conteúdo & 75 & 80 & 85 & 90 & 90 \\
\hline contribuição & 80 & 100 & 95 & 85 & 100 \\
\hline
\end{tabular}

\section{Avaliação final - Corujas}

\begin{tabular}{|c|c|c|c|c|c|}
\hline & Pandas & Guaxinin & Pantera & Corujas & Koalas \\
\hline Criatividade & 45 & 90 & 75 & 95 & 80 \\
\hline conteúdo & 50 & 90 & 90 & 95 & 95 \\
\hline contribuição & 60 & 100 & 85 & 100 & 100 \\
\hline
\end{tabular}

\section{Avaliação final - Koalas}

\begin{tabular}{|c|c|c|c|c|c|}
\hline & Pandas & Guaxinin & Pantera & Corujas & Koalas \\
\hline Criatividade & 8 & 9,5 & 7 & 10 & 10 \\
\hline conteúdo & 7 & 9 & 9 & 10 & 10 \\
\hline contribuição & 9 & 10 & 10 & 10 & 9,5 \\
\hline
\end{tabular}

\section{Avaliação final - Professora}

\begin{tabular}{|c|c|c|c|c|c|}
\hline & Pandas & Guaxinin & Pantera & Corujas & Koalas \\
\hline Criatividade & 60 & 85 & 75 & 95 & 90 \\
\hline conteúdo & 85 & 90 & 90 & 95 & 95 \\
\hline contribuição & 85 & 100 & 95 & 100 & 100 \\
\hline
\end{tabular}

Fonte. Autoria própria. 
Avaliar um aluno, em qualquer situação de aprendizagem, não é uma tarefa fácil, mas, poder acompanhar diretamente seu processo de escrita, página a página, ou seja, no momento em que o aluno está digitando e, ainda, poder auxiliá-lo em seu percurso, é, com certeza, uma forma mais fácil e coerente de avaliar.

Além disso, com a experiência de produzir textos em um ambiente digital, coletivamente e com o apoio da professora, os alunos aprenderam muito mais do que usar uma ferramenta nova, eles aprenderam novas formas de ler e de escrever.

A experiência também os tornou mais autônomos. Quando não obtinham respostas para suas dúvidas imediatamente, com um colega ou com a professora, buscavam as respostas com outras pessoas, com outros professores, com a diretora da escola, com a servente, nas saídas de campo em grupo ou por meio de pesquisas individuais através de entrevistas ou na internet. Todo esse processo foi levado em conta na avaliação. Foi oportunizado a cada aluno a participação na avaliação final, que foi dividida em três partes. Primeira: nota individual atribuída pela professora -participação, desempenho e competência comunicativa e textual; a segunda, uma nota justificada do grupo e a terceira uma autoavaliação. $\mathrm{Na}$ autoavaliação, um grupo escreveu: «pedimos que a nota da integrante Jéssica seja desigual das demais, nota 30; pois participou apenas no início do projeto", mostrando maturidade e comprometimento. A professora surpreendeu-se com as produções dos alunos, que foram bastante significativas porque eles buscaram temas concretos para as produções e, dessa forma, todos alcançaram boas notas, tanto na avaliação do texto escrito, considerando as especificidades dos gêne- ros produzidos, a adequação do discurso e a correção linguística, quanto na participação colaborativa.

Aos poucos, os alunos foram responsabilizando-se pelo trabalho e passaram a gostar mais das aulas de português. No final, os alunos, além de terem tido contato com os textos dos colegas de seu grupo, estavam em contato com a produção de todos os colegas, partilhando ideias e conhecimento, em uma atitude responsiva com o processo comunicativo, seja oral ou escrito, permeando o universo linguístico.

\section{Conclusiones}

Com esta proposta, chegou-se à produção de textos que podem ser definidos como objeto da atividade autoral de mobilização e de recursos para a realização de um projeto enunciativo a partir da relação locutor-interlocutor (Sobral, 2019). Assim, o texto deixa de ser um objeto apenas teórico, embora respeite a materialidade de sequências organizadas, com sinais convencionais, elementos linguísticos e estruturas sintáticas devidamente organizadas, produzindo sentido, em um todo coerente e coeso, e passa a ser um discurso autoral do grupo de alunos, o que se acredita que pode ser visto como uma prática que transcende a uma proposta tradicional de escola e proponha ensinar aos alunos novas formas de competências nesses tempos (Rojo, 2013).

A leitura e escrita de textos multimodais favorecem o multiletramento ampliando a competência acadêmica e discursiva dos alunos, tão necessárias para o desenvolvimentos 
das habilidades individuais. A abordagem por meio de um objeto de amplo domínio dos alunos os empodera e os estimula a participarem ativamente das aulas, pois a ferramenta, seja o celular ou tablet que utilizaram para as produções textuais respeita o desejo dos alunos, além de comprometê-los com seu processo de aprendizagem e fortalece os vínculos com os professores, ampliando a autonomia de pesquisa dos alunos.

A forma colaborativa de construção e desenvolvimento textual oportuniza um amplo aprendizado e um respeito mútuo, pois o trabalho do outro interfere na produção coletiva e melhora o individual. Cada projeto escolar deve ser pensado de acordo com o que se pretende e a partir disso se fazem escolhas para analisar o que melhor corresponde às necessidades dos alunos e professor, pois tudo muda o tempo todo e aparecem novas informações e novos desafios mostrando a importância de um trabalho que respeite novas propostas de ensino.

\section{Referencias}

Aragão, R. C. (2012). Pesquisa e Geração de Tecnologia Educacional em Ilhéus e Itabuna. Estudos IAT, 2, 190-205.

Brasil. (2018). Base Nacional Comum Curricular (BNCC). Educação é a Base. Brasília: MEC/CONSED/UNDIME.

Cope, B.; Kalantziz, M. (Eds.). (2005). Multiliteracies: Literacy Learning and the design of social futures. London: Routledge.
Esteban, M. P. (2010). Pesquisa Qualitativa em Educação. Rio de Janeiro: McGraw-Hill.

Gomes, R. (2017). Objetos de aprendizagem e novos letramentos: uma análise do objeto enem wars. Revista de Estudos Acadêmicos de Letras, 10(1), 134-153.

Kress, G.; Van Leeuwen, T. (1998). Front Pages: (The critical) analysis of newspaper layout. In A. Bell y P. Garrett (Eds.), Approaches to media discourse (pp.186-219). Oxford: Blackwell.

Lemke, J. L. (2010). Letramento metamidiático: transformando significados e mídias. Revista Trabalhos em Linguística Aplicada, 49(2), 455-479.

Oliveira, A. L. (2012). A pesquisa-ação colaborativa e a prática docente localmente situada: dois estudos em perspectiva. Calidoscópio, 10(1), 58-64. DOI: http://dx.doi.org/10.4013/ cld.2012.101.06

Paiva, V. L. (2019). Reflexões sobre ética e pesquisa. Revista Brasileira de Linguística Aplicada, 5(1), 43-61. DOI: http:// dx.doi.org/10.1590/S1984-63982005000100003.

Palfrey, J.; Gasser, U. (2011). Nascidos na era digital: Entendendo a primeira geração de nativos digitais. Porto Alegre, RS: Grupo A.

Ribeiro, A. E. (2013). Multimodalidade e produção de textos: questões para o letramento na atualidade. Signo, Santa Cruz do Sul, 38(64), 21-34. 
Rojo, R. (2018). Textos multimodais. Universidade Estadual de Campinas-UNICAMP/Instituto de Estudos da Linguagem-IEL. Disponível em http://www.ceale.fae.ufmg.br/app/webroot/ glossarioceale/verbetes/textos-multimodais

Rojo, R. H. R.. (2013). Gêneros discursivos do Círculo de Bakhtin e multiletramentos. Em R. H. R. Rojo (Org.). Escol@ conectada: Os multiletramentos e as TICs. São Paulo, SP: Parábola Editorial.

Saccol, A., Schlemmer, E.; Barbosa, J. (2010). M-learning e u-learning: novas perspectivas da aprendizagem móvel e ubíqua. São Paulo: Pearson education do Brasil.

Sobral, A. (2009). Do dialogismo ao gênero: as bases do pensamento do círculo de Bakhtin. Campinas, SP: Mercado de Letras.

Tripp, D. (1996). The SCOPE Program (An action inquiry program for supporting professional-practical workplace learning). Perth: Education Department of WA.

Tripp, D. (2005). Pesquisa-ação: uma introdução metodológica. Educação e Pesquisa, 31(3), 443-466. 